\title{
J
}

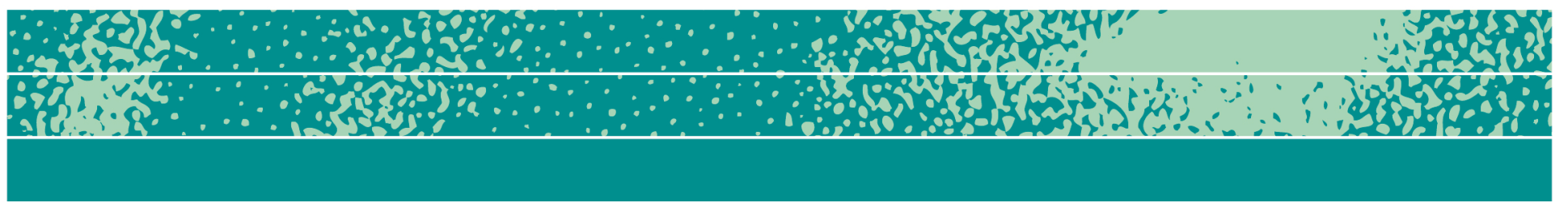

\section{Design Anthropology: An Introduction to the Themed Issue}

\author{
Christine Miller and Emilie Hitch
}

This Themed Issue is the culmination of a collective exploration of the

Page 1 of 6 emerging transdisciplinary field of Design Anthropology. The genesis of this project was a panel session sponsored by the National Association for the Practice of Anthropology (NAPA) at the American Anthropological Association (AAA) Annual Meeting in 2016. The topics of the articles range from co-designing online archives for endangered languages (Wasson, et al) to negotiating the challenges of interdisciplinary collaboration in software development (Hanson). Underpinning each of the articles are the authors' articulation of design anthropology as change-in-motion: an evolving form of praxis that incorporates design and anthropological theory and a fluid rubric of methods, tools, and perspectives.

The origins of design anthropology have been traced to the introduction of ethnography in design in the late 1970s (Wasson, 2000; Gunn, Otto, \& Smith, 2013), and the earlier influence of the work of designer/educator, Victor Papanek in the early 1960s (Clarke, 2018). Although design anthropology is often categorized as a subdiscipline of business anthropology, it has evolved as a field in its own right with a "distinct style and practice of knowledge production." (Gunn, et al, 2013: 1).
JBA 7(2): 157-162

Autumn 2018

(C) The Author(s) 2018 ISSN 2245-4217

www.cbs.dk/jba 
An obvious place to start this Introduction might be to propose a definition of design anthropology. Several have in fact been offered by our authors. However, as the field continues to evolve more is revealed about its potential as a methodology and philosophy for generating change. We agree with Otto and Smith's (2013) claim that design anthropology is "a distinct style of knowing." Design anthropology, they propose, combines the transformative, future orientation of design with anthropological theory and cultural interpretation, systematic investigation of the past as a lens to explore the present, and a "unique sensitivity to the value orientations of various groups affected by design projects - including disempowered groups, consumers, producers, and audiences" (2013: 4). An emerging set of principles further characterizes the convergence of these two distinct disciplines. These include not only those elements distinct to each field, but most importantly a transdisciplinary focus that embraces a performative, collaborative, iterative, and critical approach to exploring and reframing problems and opportunities. Encompassing a perspective that recognizes the past and its influence on the present, design anthropology "takes into account the continuous unfolding of possibilities and the implications for change on social, political, financial, economic and other dimensions for a broad range of stakeholders and for the planet" (Miller 2018: 64). This optimism, which is characteristic of design, is tempered by the anthropological grounding in empirical research and a tradition within both fields of rigorous critique.

In this Introduction, we consider existing notions of design anthropology in relation to articles by authors who represent an evolving network of interpreters of the field. The articles cover a range of themes, from the challenge of the commodification of inclusion and empathy, to the capacity to create commonality across disparate stakeholders, to issues of power, ethics, and space and time. In the following paragraphs, we highlight the elements within each article that resonate with what we know of design anthropology today. We then summarize the insights that add substance to emerging principles and characterizations of the field and suggest where it might be moving. Keeping in mind the emergent nature of design anthropology and its various manifestations, particularly on both sides of the Atlantic, our intention is to contribute to our understanding of an evolving field in motion.

\section{Themes}

As a group, the articles in this special issue highlight a number of themes that include collaborative dialog, aspirations to transdisciplinary action, and a commitment to upholding human interests ${ }^{1}$ while addressing

\footnotetext{
${ }^{1}$ Moving beyond human centered design (HCD), the posthuman paradigm is inclusive of the interests of nonhumans such as animals and machines (i.e., robots). For an example, see Laura Forlano's (2017) article "Posthumanism and
} 
institutional and corporate objectives. They have in common how the authors approach the power dynamics of applying the understanding and insights of generative research with designing "with" and "for" others and the transformative interventions that design engenders. Individually, each article presents a different configuration of the emerging principles of design anthropology: transformation, future-orientation, holism, local participation and collaboration, transdisciplinarity, performance, critique, iteration, and emergent potentiality (Miller, 2018). Although the contexts vary widely, design anthropologists engage in a distinctive practice in which elements of both anthropology and design are interwoven.

\section{Overview of the Articles}

Tamara Hale traces the diffusion of anthropological and anthropologically inspired ethnographic methods into industry, noting that product development practitioners have stripped down these methods. Through this reductive process a tendency has developed to see people in relation to a specific product or service "as 'users', 'customers' or 'clients', which results in both a simplistic and individualistic view of human experiences" (this issue p. 163). Hale proposes that service design, a design practice that shifts the focus of designing one-off products or services to systems of products, interactions and processes intended to serve the needs of ordinary people and improve their lives and wellbeing. She argues that anthropologists can bring a unique perspective to service design because of their attention to, and understanding of, whole systems. Hale illustrates by describing a series of events that occurred during a study of passengers on a 3-hour ferry crossing between Dover and Calais that led her to adopt the practice of service design.

Natalie Hanson describes the pressures within the world of software development where designers and researchers work with a technical team to animate a technology concept through a user-centered approach. Hanson prefaces a case study by providing an insider look at the context of software development with its different roles, processes, tools and practices. Set against a backdrop of urgency around innovation and speed to market, Hanson details the challenging conditions involved in navigating collaboration between social scientists and specialized designers "to bring their research and new concepts to life in a way that is 'consumable' by a variety of team members, including engineers and data scientists" (this issue p. 184).

Siobahn Gregory describes the impact of design-driven social innovation projects, specifically those tied to city-wide revitalization efforts, on neighborhood-based community groups in the JeffersonChalmers neighborhood on Detroit's east side. She makes the case that

Design." 
design anthropology as a deeper, more embedded and equitable alternative than design thinking interventions aimed as social change, may be better suited to social design process. Gregory argues that design anthropology is a social design process that would prioritize more socially transformative goals over "empathy-building" activities and design "interventions." She asserts that "Design anthropology may also produce greater social outcomes through longer-term, embedded approaches, more aligned with the work of grassroots social organizations" (this issue p. 211).

The team of Wasson, et al notes that although design anthropology practice and the employment of design anthropologists has increased in the private sector, especially in corporations and design firms, this is not the case for sectors of society that have fewer financial resources, but arguably have a greater need. She and her co-authors describe how they applied design anthropology and user-centered design (UCD) in promoting a paradigm shift in the field of language archives. Framing design anthropology and UCD as key tools, the goal of their research is to develop a set of best practice guidelines for UCD language archives.

Lisa DiCarlo explores design anthropology as a topic of study among university students. She begins by describing her first encounter with design anthropology as "a chance introduction" and wonders how students of anthropology can be entering the field without having learned about all of its practical applications. Noting that a search of the AAA website (i.e. AnthroGuide) yielded only two U.S. institutions that offer programs in design anthropology, she concludes that, "Not only are we keeping this sub-discipline a secret from our students, we are also keeping it a secret from ourselves" (this issue p. 269). Pointing out the critical importance of anthropology's theoretical contribution to design, she argues that "Anthropology is not simply the camera; it is the filter that gives depth and texture to what is viewed through the design lens. Theory becomes generative as opposed to contemplative."

Drawing on a two-year National Science Foundation funded study of collaboration with designers and design educators in four countries, Laura Forlano and Stephanie Smith raise issues related to furthering the transdisciplinarity of design anthropology. Citing Gunn et al, they note that design anthropology offers the opportunity to change the relationship between theory and practice and to develop critical practices of "collaborative future making" (2013) that incorporate discussions around practice-based design research. Forlano and Smith assert that "in order to create transdisciplinary practices around collaboration for design anthropology, the field must understand existing practices of critique in the field of design" (this issue p. 279). Their article describes "the culture of critique that underpins the collaborative practices of designers", noting in particular "designers often participate in a studiobased culture of critique, which is learned in art and design schools, even 
when it is not explicitly taught" (this issue p. 279). They argue that the emergent practice of critique as collaboration is an important consideration, especially as design anthropology matures to encompass virtual design teams enabled by digital platforms that allow for distributed collaboration.

\section{In Closing}

Design anthropology as a practice has emerged over the past few decades. While it was not uncommon for anthropologists and designers to work together on individual projects, Murphy and Marcus (2013) note that the nature of these partnerships was often interdisciplinary, the goal being to enhance the design of "things" or to make incremental improvements or upgrades to pre-existing products. "Not until very recently, however, has there been much of an attempt to formalize this relationship as a cohesive field of its own, with a common body of knowledge, methods, and research assumptions shared by a like-minded community of practitioners" (2013: 251). Our intention for this special issue is to contribute to the ongoing development of design anthropology as a transdisciplinary field that not only recognizes and draws on its roots, but also maintains its essential exploratory and experimental nature going forward. Formalization of the field comes as a result and articulation of informal exploration and experimentation.

In closing, we want to take this opportunity to offer our sincere thanks to our authors and reviewers for their untiring efforts and commitment to seeing this project to completion. We hope this collection of articles will provide inspiration to anyone who feels drawn to explore beyond the boundaries of their native discipline, to those who are looking for a path to a holistic understanding of the collective challenges we face in contemporary society. 


\section{References}

Clarke, A.J. 2018b. "Introduction." In Design Anthropology: Object

Cultures in Transition, Clarke, A.J. (ed.), xv-xxv. New York: Bloomsbury.

Forlano, L. 2017. "Posthumanism and Design." She Ji (1), 16-29.

Miller, C. 2018. Design + Anthropology: Converging Pathways in Anthropology and Design. New York: Taylor and Francis/Routledge. https://doi.org/10.4172/2332-0915.1000198

Otto, T. and Smith, R.C. 2013. "A Distinct Style of Knowing." In Design Anthropology: Theory and Practice Gunn, W., Otto, T., \& Smith, R.C. (eds.), 1-29. New York: Bloomsbury.

Wasson, C. 2000. "Ethnography in the Field of Design." Human Organization 59(4), 377-388. https://doi.org/10.17730/humo.59.4.h13326628n127516

Christine Miller, Ph.D. is a researcher and educator working at the intersection of anthropology, design and business. Her ethnographic study of process formalization and the relationship between innovation and formalization at a Tier One automotive supplier focused on the social and organizational dimensions of innovation processes. As a design anthropologist, her work is explicitly interventionist and transformative, which allows her to engage in all phases of the design process. Her research interests include socio-technical systems and the ways in which sociality and culture influence the design and adoption/adaptation of new products, processes, and technologies. She is also interested in communication and knowledge flows, especially between diverse groups, and collaborative innovation networks (COINs). Chris is currently a Co-PI on an NSF study of Ethics in STEM research ("A Bottom-Up Approach to Enhancing a Culture of Responsible Research and Practice in STEM" NSF Award \#1635661).

Emilie Hitch has worked with advertising agencies, Human-Centered Design labs and strategy groups dedicated to cultural change all over the world with Thinkers \& Makers. She has led ethnographic, innovation, and strategic planning projects for many industry clients such as Nike Bauer and Land O'Lakes, as well as NGOs such as The University of Minnesota, The Quetico Superior Foundation, and growers' associations across the world. From designing a new way to engage with the public for the Minnesota Department of Transportation to co-creating a new model of philanthropy with Eat for Equity, her work is always rooted in anthropology, strategy and the common Good. A graduate of Yale and the London School of Economics with degrees in anthropology, Emilie also holds a master's degree from the Humphrey School of Public Affairs at the University of Minnesota. 